\title{
Predictive factors for preeclampsia in pregnant women: a Receiver Operation Character approach
}

Ashraf Direkvand-Moghadam ${ }^{1,2}$, Afra Khosravi ${ }^{3}$, Kourosh Sayehmiri ${ }^{1,4}$

1Psychosocial Injuries Research Center, Ilam University of Medical Sciences, Ilam, Iran 2Department of Midwifery, Faculty of Nursing and Midwifery, Ilam University of Medical Sciences, Ilam, Iran

${ }^{3}$ Department of Immunology, Faculty of Medicine, Ilam University of Medical Sciences, Ilam, Iran

${ }^{4}$ Department of Social Medicine, Faculty of Medicine, Ilam University of Medical

Sciences, Ilam, Iran

Submitted: 2 June 2012

Accepted: 8 December 2012

Arch Med Sci 2013; 9, 4: 684-689

DOI: 10.5114 /aoms.2013.36900

Copyright (c) 2013 Termedia \& Banach

\section{Abstract}

Introduction: Preeclampsia is a major cause of maternal and prenatal mortality and morbidity worldwide. There are some risk factors that are of great value for prediction of preeclampsia by which the practitioners can counsel women regarding this disease. The aim of this study was to analyze the role of such risk factors as the predictors associated with preeclampsia among Iranian women using logistic regression.

Material and methods: The role of some risk factors such as demographic, anthropometric, medical and obstetrics variables in preeclampsia among 610 women attending the obstetric ward of Mustafa hospital in Ilam in the west of Iran was analyzed from May to September 2010. All the pregnant women referred to this hospital participated in the study except those cases that had abortion. Unvaried and Multiple logistic regression analyses were used to find the predictive factors behind preeclampsia. Standard errors of area compute using nonparametric methods. A $p$-value of 0.05 was considered statistically significant.

Results: Prevalence of preeclampsia was 9.5\% (95\% Cl 7.4-11.6\%). Predictive model build using history of preeclampsia, history of hypertension, and history of infertility. Area Under the Receiver Operation Character (AUROC) was estimated $0.67(95 \% \mathrm{Cl} 0.59-0.67, p<0.01)$ that showed that using the model is much better than having a guess.

Conclusions: The odd of preeclampsia increased in women with a history of preeclampsia, hypertension and infertility. Recognition of these predictor factors would improve the ability to diagnose and monitor women likely to develop preeclampsia before the onset of disease for timely interventions.

Key words: independent predictive factors, preeclampsia, risk factors.

\section{Introduction}

Preeclampsia (PE) is a pregnancy-specific syndrome [1] and it is characterized by the new onset of hypertension and proteinuria after the $20^{\text {th }}$ week of gestation in women who previously were normotensive [2]. Preeclampsia complicates about 3\% of all pregnancies [3]. Although the estimated incidence of PE is $6-10 \%$ of all pregnancies in the United States, the incidence is believed to be even higher in underdeveloped countries [4] and the studies estimate even a higher rate for countries like Iran, even

\section{Corresponding author:}

Afra Khosravi

Department of Immunology

Faculty of Medicine

Ilam University

of Medical Sciences

Ilam, Iran

Phone/fax: +98 8412227140

+98918 7419472

E-mail: afra@medilam.ac.ir,

afrakhosravi@yahoo.co.uk 
though there are different incidence rates reported $[5,6]$. Preeclampsia is a major cause of maternal and prenatal mortality and morbidity [7]. Previous studies indicated that PE increases the risk of later cardiovascular disease [8] and increases the overall risk of cancer [9]. There is significant progress towards a comprehensive understanding of the cause of PE and the contribution of circulating factors $[10,11]$. Recent studies have indicated the involvement of hemoglobin $(\mathrm{Hb})$-induced oxidative stress in the development of PE. Also increased levels of free fetal hemoglobin ( $\mathrm{HbF}$ ), total $\mathrm{Hb}$, and markers for oxidative stress as well as the hemescavenger and antioxidant endogenous protein 1-microglobulin (A1M) have been found to be elevated at term in both plasma and placenta from women with PE [12]. A burst of oxidative stress occurs in the normal placenta as the maternal circulation is established that may serve a physiological role in stimulating normal placental differentiation, but may also be a factor in the pathogenesis of PE and early pregnancy failure if antioxidant defenses are depleted [13]. Studies have suggested several risk factors for PE including nulliparity family or own history of PE, diabetes, body mass index (BMI) higher than normal, multiple pregnancy, maternal age (less than 20 or greater than 35 years), renal disease, hydatidiform mole, hydrops fetalis, oocyte donation or donor insemination, chronic hypertension and chronic autoimmune disease [14-16]. Multiple logistic regression analysis showed that the history of $P E$ in previous pregnancy $(O R=23.7$, $p<0.001)$ and familiar history of PE $(\mathrm{OR}=1.62$, $p<0.08)$ and $\mathrm{BMI}(\mathrm{OR}=1.60)$ were the main risk factors for PE [17]. Preeclampsia biochemical markers in general and first trimester PE biochemical markers specifically have been investigated. Categories including angiogenic/antiangiogenic factors, placental proteins, $\mathrm{HbF}$, kidney markers, ultrasound and maternal risk factors were described. The specific biochemical markers discussed were PAPP-A, s-Flt-1/PIGF, s-endoglin, PP13, cystatin-C, HbF, and a1-microglobulin (A1M). PAPP-A and HbF both show potential as predictive biochemical markers in the first trimester with $70 \%$ sensitivity at $95 \%$ specificity. However, PAPP-A was not PE-specific and needs to be combined with Doppler ultrasound to obtain the same sensitivity as HbF/A1M. It has been proposed that soluble Flt-1 and PIGF are promising biochemical markers that together show high sensitivity from the mid-second trimester though PIGF is somewhat useful from the end of the first trimester [12]. The concept of a two-stage model of PE that was originally introduced by Redman et al. could be a helpful means to predict PE as a twostage disorder. The first stage was reduced placental perfusion that led to the maternal syndrome, stage 2 . There are some modifications made by
Roberts et al. to this two-stage model that have important implications [18]. Evidence that placentation is abnormal earlier in pregnancy may provide a better opportunity for therapeutic interventions to prevent stage 2. Evidence that not all pregnancies associated with abnormal implantation (at least as measured by uterine artery Doppler and placental markers) have abnormal pregnancy outcomes suggests a search for what is different in these pregnancies. The two-stage model as modified remains useful conceptually to approach studies of PE and other implantation disorders [18].

As PE remains a serious and poorly understood complication of pregnancy, it is necessary to recognize the epidemiological and clinical risk factors to predict the disease before it threatens the survival of both the mother and the fetus. The present study was conducted to determine the predictive factors for PE, in Iranian women referred to the Mustafa Hospital of Ilam, Iran.

\section{Material and methods}

The role of demographic, anthropometric, medical and obstetrics variables in prediction of $\mathrm{PE}$ among women attending the obstetric ward of the Mustafa Hospital of Ilam in the west of Iran, from May 2010 to September 2010, was evaluated. All the pregnant women who were referred to the hospital during that period participated in the study except those who had an abortion. Sample size was calculated according to systematic random sampling where $P$ (prevalence of $\mathrm{PE}$ ) was $10 \%$ and maximum estimate error was $2.4 \%$.

Subjects were divided into two groups: women without PE and women with PE at the time of referring to the hospital. Preeclampsia was defined by the International Society for the Study of Hypertension in Pregnancy (ISSHP) as a multi-system disorder unique to human pregnancy characterized by hypertension and involvement of one or more other organ systems and/or the fetus. A diagnosis of PE can be made when hypertension arises after 20 weeks gestation and is accompanied by one or more of the following: urine protein/creatinine ratio $\geq 30 \mathrm{mg} / \mathrm{mmol}$, serum or plasma creatinine $>90 \mu \mathrm{mol} / \mathrm{l}$, oliguria, thrombocytopenia, hemolysis, disseminated intravascular coagulation, raised serum transaminases, severe epigastric or right upper quadrant pain, severe headache, persistent visual disturbances (photopsia, scotomata, cortical blindness, retinal vasospasm), stroke, pulmonary edema, fetal growth restriction, placental abruption [19].

\section{Statistical analysis}

Results are expressed as mean \pm standard deviation. Kolmogorov-Smirnov test was used to test 
the normality in continues variables. Independent $t$-test was used to compare the mean BMI and age in two groups (with PE vs. without PE). Chi-square $\left(\chi^{2}\right)$ test was used to explore the relationship between occupation, type of pregnancy, type of the previous delivery, contraceptive method and PE. Both univariate and multiple logistic regression analyses were used to indicate the association between the dependent (with PE vs. without PE) and independent variables. The forward likelihood ratio (LR) method was used to choose the best multivariate logistic regression model in independent variables such as education, BMI, number of pregnancies, abortion and parity. Predicted probability for PE was computed using the multivariate logistic model. AUROC was applied to compare the accuracy of the model. A $p$-value less than 0.05 was considered as the significance level. All the statistical analyses were performed using SPSS package version 16.

\section{Measures}

Data collection and examinations were carried out by a face-to-face interview that was carried out by a trained midwife. Demographic data including age, education, and occupation and anthropometric data including weight and height were assessed. Height and weight were measured employing Seca 220 (Germany) by a trained researcher when the subjects were minimally clothed without shoes before pregnancy or during the first trimester of pregnancy. The body mass index was calculated based on the heights and the weights $(\mathrm{BMI}=$ weight $(\mathrm{kg}) /\left(\right.$ height $\left.(\mathrm{m})^{2}\right)$. Based on BMI, women were grouped into different categories as recommended by the National Centre for Education in Maternal and Child Health. The clinical measures including the history of pregnancy, abortion, parity and medical conditions such as chronic hypertension, diabetes mellitus and renal disease were collected by an observational interview.

\section{Ethics}

The Ethics Committee of Ilam University of Medical Sciences approved the study design. Written informed consent was obtained from the participants after comprehensive explanation of the procedure involved.

\section{Results}

In total 610 pregnant women participated in the study excluding those who had an abortion or were under 20 weeks of gestational age. $90.5 \%$ of all participants were normal while $9.5 \%$ (95\% Cl 7.4-11.6\%) had PE (1.3\% mild and $8.2 \%$ severe). The sociodemographics, medical, obstetric and antenatal characteristics of all the participants are presented in Table I. A significant relationship was found between education and PE so that the risk of PE increased 4 times in the illiterate women compared to the women with an academic education. The mean age of the participants with PE was $28 \pm 5.3$ and $28.9 \pm 4.8$ for the normal group. There were no significant differences for the mean age between the two groups $(p=0.170)$. The results obtained from the logistic regression analysis indicated that there was no significant relationship between age and $\mathrm{PE}(\mathrm{OR}=0.96, p=0.17)$.

Independent samples $t$-test indicated that there was no significant difference for the BMI of the two groups. There was no statistical significance observed between the occupation, type of pregnancy, type of previous delivery, contraceptive method and PE (Table I).

Univariate logistic regression analysis showed that there was a significant association between $\mathrm{PE}$ and education ( $\mathrm{OR}=4.05$ illiterate vs. academic), history of PE (OR $=7.7)$, history of hypertension $(\mathrm{OR}=1.38)$ and history of infertility $(\mathrm{OR}=3.03)$ (Table II).

With the multivariate logistic regression analysis, history of PE $(O R=5.46)$, history of hypertension $(O R=2.34)$, and history of infertility $(O R=2.76)$ were considered as independent predictive variables for PE (Table III). The multivariate logistic model for the probability of PE and the other covariates was estimated as: $\ln (p / 1-p)=0.74-1.016$ priori inferertility; 0.72 chronic hypertension; 1.69 prior preeclampsia, where $p$ is probability of occurrence of PE. The coefficients of the logistic regression model showed that history of PE was the most important variable to predict PE. To compute the overall percentage of correct classification of the model, predicted values were compared to the observed values. Overall percentage of correct classification of the model was $90.7 \%$. It means that, knowing the history of PE, hypertension, and infertility, the ability of the model to predict the actual category of the cases is $90.7 \%$. The AUROC criterion was used to compute both the sensitivity and the specificity of the model. AUROC was estimated to be 0.67 (95\% Cl 0.59-0.76, asymptotic significance $p<0.001)$. The area under the curve represents the probability that the model predicted for a randomly chosen positive case will exceed the result for a randomly chosen negative case. The asymptotic significance is less than 0.05 , which means that using the model is a good means to predict PE (Figure 1).

\section{Discussion}

There was no significant relationship between maternal age and PE $(P=0.17)$, which is in agreement with the results of some studies [20,21] while it was different from the results observed by anoth- 
Table I. Comparison of characteristics between groups

\begin{tabular}{|c|c|c|c|}
\hline \multirow[t]{2}{*}{ Characteristic } & \multicolumn{2}{|c|}{ Groups } & \multirow{2}{*}{$\begin{array}{l}\text { Value } \\
\text { of } p\end{array}$} \\
\hline & $\begin{array}{l}\text { Normal } \\
(n=552 \\
90.5 \%)\end{array}$ & $\begin{array}{l}\text { Preeclampsia } \\
\qquad \begin{array}{c}(n=58 \\
9.5 \%)\end{array}\end{array}$ & \\
\hline BMI [kg/m²] & & & 0.236 \\
\hline Lightweight (>19.8) & $61(16.95 \%)$ & $7(20.59 \%)$ & \\
\hline Normal (19.8-25.9) & $196(54.45 \%)$ & $20(58.81 \%)$ & \\
\hline Overweight (26-29) & 56 (15.55\%) & $1(2.94 \%)$ & \\
\hline Obese $(<29)$ & 47 (13.05\%) & $6(17.64 \%)$ & \\
\hline Education & & & 0.041 \\
\hline Illiterate & 37 (6.70\%) & $10(17.24 \%)$ & \\
\hline Reading and writing & g 53 (9.60\%) & $4(6.9 \%)$ & \\
\hline Primary & 75 (13.59\%) & $4(6.9 \%)$ & \\
\hline $\begin{array}{l}\text { Secondary school } \\
\text { education }\end{array}$ & 87 (15.77\%) & 7 (12.06\%) & \\
\hline High school & 240 (43.48\%) & $29(50 \%)$ & \\
\hline Academic & $60(10.86 \%)$ & $4(6.9 \%)$ & \\
\hline Occupation & & & 0.090 \\
\hline Homemaker & 533 (97.26\%) & 52 (92.86\%) & \\
\hline Employed & $15(2.74 \%)$ & $4(7.4 \%)$ & \\
\hline Pregnancy & & & 0.001 \\
\hline Primigravida & 267 (48.55\%) & 27 (46.55\%) & \\
\hline 2-5 pregnancies & 247 (44.91\%) & $29(50 \%)$ & \\
\hline$>5$ pregnancies & $36(6.54 \%)$ & $2(3.45 \%)$ & \\
\hline Type of pregnancy & & & 0.610 \\
\hline Accepted & $442(80.07 \%)$ & 45 (77.59\%) & \\
\hline Unwanted & $110(19.93 \%)$ & $13(22.41 \%)$ & \\
\hline Prenatal care & & & 0.003 \\
\hline Partially done & $8(1.45 \%)$ & $1(1.72 \%)$ & \\
\hline Completed & $542(98.55 \%)$ & 57 (98.28\%) & \\
\hline Abortion & & & 0.024 \\
\hline Without & 481 (88.26\%) & $50(86.20 \%)$ & \\
\hline 1 Abortion & 59 (10.82\%) & 5 (8.62\%) & \\
\hline 2 Abortions & $5(0.92 \%)$ & $3(5.18 \%)$ & \\
\hline Parity & & & 0.022 \\
\hline Primiparous & 270 (49.54\%) & 30 (51.72\%) & \\
\hline 2-5 parity & 261 (47.89\%) & 28 (48.28\%) & \\
\hline$>5$ parity & $14(2.57 \%)$ & $0(0 \%)$ & \\
\hline
\end{tabular}

\begin{tabular}{|c|c|c|c|}
\hline \multirow[t]{2}{*}{ Characteristic } & \multicolumn{2}{|c|}{ Groups } & \multirow{2}{*}{$\begin{array}{c}\text { Value } \\
\text { of } p\end{array}$} \\
\hline & $\begin{array}{l}\text { Normal } \\
(n=552 ; \\
90.5 \%)\end{array}$ & $\begin{array}{l}\text { Preeclampsia } \\
\quad(n=58 \\
9.5 \%)\end{array}$ & \\
\hline \multicolumn{3}{|l|}{ New born gender } & 0.430 \\
\hline Male & \multicolumn{3}{|c|}{296 (54.81\%) 27 (47.36\%) } \\
\hline Female & \multicolumn{2}{|c|}{244 (45.18\%) 30 (53.64\%) } & \\
\hline \multicolumn{3}{|l|}{ Contraceptive method } & 0.202 \\
\hline Contraceptive pill & \multicolumn{3}{|c|}{$254(57.20 \%) 17(32.07 \%)$} \\
\hline Condom & \multicolumn{3}{|c|}{60 (13.51\%) $8(15.09 \%)$} \\
\hline IUD & \multicolumn{3}{|c|}{$13(2.93) \quad 2(3.77 \%)$} \\
\hline DMPA & \multicolumn{3}{|c|}{$7(1.58 \%) \quad 2(3.77 \%)$} \\
\hline Withdrawal & \multicolumn{3}{|c|}{87 (19.60\%) 11 (20.75\%) } \\
\hline $\begin{array}{l}\text { No method } \\
\text { of contraception }\end{array}$ & \multicolumn{2}{|c|}{$23(5.19 \%) \quad 13(24.54 \%)$} & \\
\hline \multicolumn{3}{|l|}{ History of infertility } & 0.004 \\
\hline Yes & $44(8.07 \%)$ & $12(20.69 \%)$ & \\
\hline No & \multicolumn{3}{|c|}{505 (91.93\%) 46 (79.31\%) } \\
\hline \multicolumn{3}{|c|}{ Relative of the partner } & 0.513 \\
\hline Yes & \multicolumn{3}{|c|}{$148(26.96 \%) 16(27.58 \%)$} \\
\hline No & \multicolumn{3}{|c|}{401 (73.04\%) 42 (72.41\%) } \\
\hline \multicolumn{3}{|l|}{$\begin{array}{l}\text { Medical disorders } \\
\text { cardiovascular disease }\end{array}$} & 0.402 \\
\hline Yes & $9(1.64 \%)$ & $0(0 \%)$ & \\
\hline No & \multicolumn{3}{|c|}{$540(98.36 \%) 58(100 \%)$} \\
\hline \multicolumn{3}{|l|}{ Diabetes mellitus } & 0.532 \\
\hline Yes & $45(8.2 \%)$ & $5(8.62 \%)$ & \\
\hline No & $504(91.8 \%)$ & $53(93.38 \%)$ & \\
\hline \multicolumn{4}{|l|}{ Immune disorders } \\
\hline Yes & $0(0 \%)$ & $0(0 \%)$ & \\
\hline \multicolumn{3}{|l|}{ Renal disorders } & 0.424 \\
\hline Yes & $57(10.38 \%)$ & $8(13.8 \%)$ & \\
\hline No & \multicolumn{3}{|c|}{$492(89.62 \%) 50(86.2 \%)$} \\
\hline \multicolumn{3}{|c|}{ History of hypertension } & 0.001 \\
\hline Yes & $50(0.91 \%)$ & $14(24.13 \%)$ & \\
\hline No & \multicolumn{3}{|c|}{499 (99.09\%) 44 (75.87\%) } \\
\hline \multicolumn{3}{|l|}{ History of preeclampsia } & $<0.001$ \\
\hline Yes & $23(4.21 \%)$ & $15(25.86 \%)$ & \\
\hline No & $523(95.79 \%)$ & $43(74.14 \%)$ & \\
\hline
\end{tabular}

er study [22]. Such difference could be due to the nature of the population-based and the hospitalbased studies.

Although in our study there was not a significant relationship between $\mathrm{BMI}$ and $\mathrm{PE}$, another study reported opposite results [21, 22]. This study deter-

mined that histories of PE, hypertension and infertility are important predictive factors for PE. Our study population consisted of 610 women, including 38 women who had a history of PE and 572 women with no history of PE. A strong relationship between the history and the recurrence risk of $P E$ 
Table II. Association between preeclampsia and other variables using univariate logistic regression analysis

\begin{tabular}{|lcccc|}
\hline Variable & $B$ & S.E. & OR $(95 \% \mathrm{Cl})$ & Value of $p$ \\
\hline Education & & & & \\
\hline Illiterate & 1.40 & 0.63 & $4.05(1.18-13.86)$ & 0.026 \\
\hline Reading and writing & 0.12 & 0.73 & $1.13(0.270-4.75)$ & 0.865 \\
\hline Primary & -0.22 & 0.73 & $0.8(0.19-3.33)$ & 0.759 \\
\hline Secondary school & 0.19 & 0.65 & $1.21(0.34-4.30)$ & 0.772 \\
\hline High school & -2.71 & 0.52 & $1.81(0.61-5.35)$ & 0.282 \\
\hline Academic & & 1.0 & 0.059 & \\
\hline \begin{tabular}{l} 
History of preeclampsia \\
\hline Yes vs. no
\end{tabular} & 2.1 & 0.36 & $7.70(3.8-16.6)$ & \\
\hline \begin{tabular}{l} 
History of hypertension \\
\hline Yes vs. no
\end{tabular} & 1.15 & & & 0.001 \\
\hline \begin{tabular}{l} 
History of infertility \\
\hline Yes vs. no
\end{tabular} & 1.1 & 0.341 & $3(1.49-6.1)$ & \\
\hline
\end{tabular}

Cl-confidence interval

Table II. Association between preeclampsia and other variables using univariate logistic regression analysis

\begin{tabular}{|lcccc|}
\hline Variable & $B$ & S.E. & OR $(95 \% \mathrm{Cl})$ & Value of $p$ \\
\hline $\begin{array}{l}\text { History of preeclampsia } \\
\text { Yes vs. no }\end{array}$ & 1.697 & 0.402 & $5.46(2.48-12.1)$ & $<0.001$ \\
\hline $\begin{array}{l}\text { History of hypertension } \\
\text { Yes vs. no }\end{array}$ & 0.729 & 0.389 & $2.34(1.034-4.4)$ & 0.001 \\
\hline $\begin{array}{l}\text { History of infertility } \\
\text { Yes vs. no }\end{array}$ & 1.016 & 0.382 & $3.07(1.3-5.8)$ & 0.002 \\
\hline
\end{tabular}

Cl-confidence interval

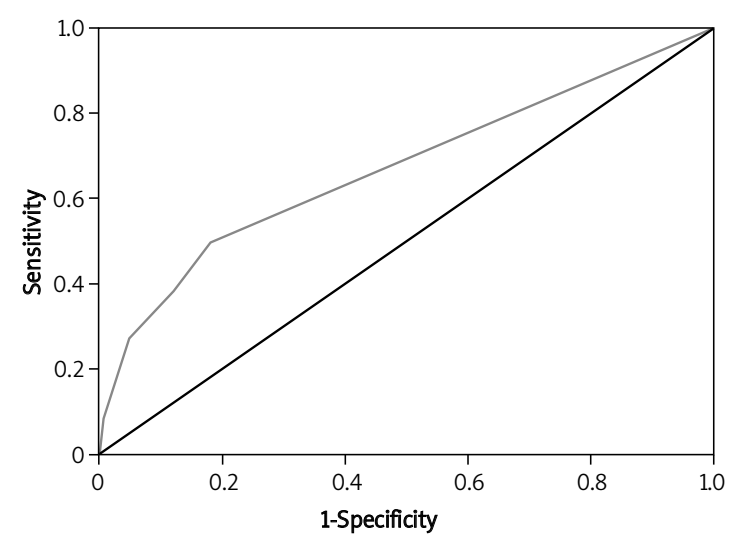

Figure 1. ROC of predicted probabilities of multivariate logistic model

has been reported by many researchers $[5,14,17$, 23]. Some studies reported that $65 \%$ of all studied women with a history of PE at the second trimester showed recurrent PE at their subsequent pregnancies [4]. In another study the recurrent risk of PE was inversely related to the gestational age at the first delivery and it was $38.6 \%$ in women whose previous delivery was less than 28 weeks compared to
$29.1 \%$ in women who had a previous delivery at 2932 weeks [23]. Chronic hypertension is a common problem in developing countries in non-pregnant women and increases the incidence of PE [21]. We found that chronic hypertension is one of the main determinants of PE in our population, as women with a history of hypertension had 1.38 times the risk of PE compared to the normal women. Our observation is in agreement with the results of several other studies [14, 16, 24]. In another study the prevalence of chronic hypertension was higher in women who developed PE than women who did not (12.1\% vs. 0.3\%) [7]. Odegard et al. in a nested casecontrol study compared 323 preeclamptic women with 650 healthy women, finding that the risk of development of PE in later pregnancy is significantly higher in women with systolic blood pressure $\geq 130 \mathrm{~mm}$ Hg compared to blood pressure < 110 $\mathrm{mm} \mathrm{Hg}$ at the first visit before 18 weeks $(\mathrm{OR}=3.6$, $95 \% \mathrm{Cl}=2.0-6.6)$ [25].

In the present study, 66 (10.81\%) of all participants were pregnant with assisted reproductive technology. The multivariate logistic regression analysis revealed an increased risk of PE in women who had been treated for infertility $(O R=3.07$; 
$95 \% \mathrm{Cl} 1.3-5.8)$. This finding of the current study is in agreement with the finding of another study [26].

There are several causative factors for infertility among which polycystic ovary disease is common. Women who have an increased risk of PE as well as a higher incidence of metabolic disturbances that have been associated with PE are also at risk of infertility [27]. In a study, the risk of PE was estimated in 20846 primiparous women according to the history of spontaneous and induced abortions. The results of this study showed that although there was not a significant association between miscarriage and PE, the risk of PE was increased in women with a history of infertility [28].

In conclusion, in view of the above findings, there are several risk factors for PE. It seems that history of $P E$, hypertension and infertility are some independent predictive variables. It is concluded that pregnant women at risk of PE should be identified and high-quality antenatal care should be given in order to minimize the complications of PE both for the mother and the fetus.

\section{Acknowledgments}

We thank the research deputy of Ilam University of Medical Sciences for approval of this project. We thank the mothers, midwives and obstetricians at the Mustafa Hospital for their cooperation and support.

\section{References}

1. Backes CH, Markham K, Moorehead P, Cordero L, Nankervis CA, Giannone PJ. Maternal preeclampsia and neonatal outcomes. J Pregnancy 2011; 2011: 214365.

2. Wagner LK. Diagnosis and management of preeclampsia. Am Fam Physician 2004; 70: 2317-24.

3. Conde-Agudelo A, Villar J, Lindheimer M. Maternal infection and risk of preeclampsia: systematic review and metaanalysis. Am J Obstet Gynecol 2008; 198: 7-22.

4. Sibai BM. Diagnosis and management of gestational hypertension and preeclampsia. Obstet Gynecol 2003; 102: 181-92.

5. Savaj S, Vaziri N. An overview of recent advances in pathogenesis and diagnosis of preeclampsia. Iran J Kidney Dis 2012; 6: 334-8.

6. Tara F, Maamouri G, Rayman MP, et al. Selenium supplementation and the incidence of preeclampsia in pregnant Iranian women: a randomized, double-blind, placebo-controlled pilot trial. Taiwan J Obstet Gynecol 2010; 49: 181-7.

7. Duckitt K, Harrington D. Risk factors for pre-eclampsia at antenatal booking: systematic review of controlled studies. BMJ 2005; 330: 565.

8. Bellamy L, Casas JP, Hingorani AD, Williams DJ. Preeclampsia and risk of cardiovascular disease and cancer in later life: systematic review and meta-analysis. BMJ 2007; 335: 974.

9. Paltiel O, Friedlander Y, Tiram E, Barchana M, Xue X, Harlap S. Cancer after pre-eclampsia: follow up of the Jerusalem perinatal study cohort. BMJ 2004; 328: 919.

10. Sibai B, Dekker G, Kupferminc M. Pre-eclampsia. Lancet 2005; 365: 785-99.
11. Gilbert JS, Ryan MJ, LaMarca BB, Sedeek M, Murphy SR, Granger JP. Pathophysiology of hypertension during preeclampsia: linking placental ischemia with endothelial dysfunction. Am J Physiol Heart Circ Physiol 2008; 294; H541-50.

12. Anderson UD, Olsson MG, Rutardottir S, et al. Fetal hemoglobin and alpha1-microglobulin as first- and early second-trimester predictive biomarkers for preeclampsia. Am J Obstet Gynecol 2011; 204: 520 e1-5.

13. Jauniaux E, Watson A, Hempstock J, Bao Y, Skepper J, Burton G. Onset of maternal arterial blood flow and placental oxidative stress. A possible factor in human early pregnancy failure. Am J Pathol 2000; 157: 2111-22.

14. Mostello D, Catlin TK, Roman L, Holcomb WL Jr, Leet T. Preeclampsia in the parous woman: who is at risk? Am J Obstet Gynecol 2002; 187: 425-9.

15. Bulletin AP. Diagnosis and management of preeclampsia and eclampsia. Obstet Gynecol 2002; 99: 159-67.

16. Dekker G, Sibai B. Primary, secondary, and tertiary prevention of pre-eclampsia. Lancet 2001; 357: 209-15.

17. Gonzalez AL, Ulloa Galvan G, Alpuche G, Romero Arauz JF. Risk factors for preeclampsia. Multivariate analysis. Ginecol Obstet Mex 2000; 68: 357-62.

18. Roberts JM, Hubel CA. The two stage model of preeclampsia: variations on the theme. Placenta 2009; 30 Suppl A: S32-7.

19. Brown MA, Lindheimer MD, de Swiet M, Van Assche A, Moutquin JM. The classification and diagnosis of the hypertensive disorders of pregnancy: statement from the International Society for the Study of Hypertension in Pregnancy (ISSHP). Hypertens Pregnancy 2001; 20: 9-14.

20. Shamsi U, Hatcher J, Shamsi A, Zuberi N, Qadri Z, Saleem S. A multicentre matched case control study of risk factors for preeclampsia in healthy women in Pakistan. BMC Womens Health 2010; 10: 14.

21. Ganesh KS, Unnikrishnan B, Nagaraj K, Jayaram S. Determinants of pre-eclampsia: a case-control study in a District Hospital in South India. Indian J Community Med 2011; 35: 502-5.

22. Macdonald-Wallis C, Lawlor DA, Heron J, Fraser A, Nelson SM, Tilling K. Relationships of risk factors for preeclampsia with patterns of occurrence of isolated gestational proteinuria during normal term pregnancy. PLoS One 2011; 6: e22115.

23. Mostello D, Kallogjeri $D$, Tungsiripat R, Leet T. Recurrence of preeclampsia: effects of gestational age at delivery of the first pregnancy, body mass index, paternity, and interval between births. Am J Obstet Gynecol 2008; 199: 55 e1-7.

24. Qiu C, Williams MA, Leisenring WM, et al. Family history of hypertension and type 2 diabetes in relation to preeclampsia risk. Hypertension 2003; 41: 408-13.

25. Odegard RA, Vatten LJ, Nilsen ST, Salvesen KA, Austgulen R. Risk factors and clinical manifestations of preeclampsia. BJOG 2000; 107: 1410-6.

26. Lachmeijer AM, Crusius JB, Pals G, Dekker GA, Arngrimsson R, ten Kate LP. Polymorphisms in the tumor necrosis factor and lymphotoxin-alpha gene region and preeclampsia. Obstet Gynecol 2001; 98: 612-9.

27. Veltman-Verhulst SM, van Rijn BB, Westerveld HE, et al. Polycystic ovary syndrome and early-onset preeclampsia: reproductive manifestations of increased cardiovascular risk. Menopause 2010; 17: 990-6.

28. Trogstad L, Magnus P, Moffett A, Stoltenberg C. The effect of recurrent miscarriage and infertility on the risk of preeclampsia. BJOG 2009; 116: 108-13. 